The University of Southern Mississippi The Aquila Digital Community

Faculty Publications

$12-1-2005$

\title{
More Than Fun and Games: Reconsidering the Virtues of Strategic Management Simulations
}

Ken E. Zantow

University of Southern Mississippi, ken.zantow@usm.edu

Dave S. Knowlton

Southern Illinois University-Edwardsville

David C. Sharp

University of Southern Mississippi

Follow this and additional works at: https://aquila.usm.edu/fac_pubs

Part of the Business Administration, Management, and Operations Commons

\section{Recommended Citation}

Zantow, K. E., Knowlton, D. S., Sharp, D. C. (2005). More Than Fun and Games: Reconsidering the Virtues of Strategic Management Simulations. Academy of Management Learning \& Education, 4(4), 451-458.

Available at: https://aquila.usm.edu/fac_pubs/2574 


\title{
More Than Fun and Games: Reconsidering the Virtues of Strategic Management Simulations
}

\author{
KENNETH ZANTOW \\ University of Southern Mississippi \\ DAVE S. KNOWLTON \\ Southern Illinois University-Edwardsville \\ DAVID C. SHARP \\ University of Southern Mississippi
}

\begin{abstract}
We look at the relationship between business simulations and the educational theory of generative learning using the framework developed by Wittrock (1974, 1990, 1992). Our findings reveal opportunities for generative learning that occur at all phases of the simulation process. Awareness of these opportunities prepares faculty to get the most from the strategic decision-making simulations, and may assist them in defining the contribution associated with their use. We suggest areas for additional research.
\end{abstract}

There is little doubt that simulations have been used to bring to the classroom various aspects of the business world (Foria, 1990; Foria \& Wellington, 2004), and that business faculty recognize that they have value (see, e.g., Puto, 2004). If nothing else, an informal review of The Association for Business Simulation and Experiential Learning's (n.d.) website evidences a widespread existence of simulations, with over 30 simulation packages listed, each providing students with simulated experiences in a broad range of business topics, including business policy and strategy, human resources, marketing, information systems, and accounting. However, neither the faculty's recognition of value, nor their widespread use, is indicative of the true educational worth of simulations. Superficially, simulations provide a hiatus for students (and professors) from lecture and more traditional educational activities. More substantially, they provide students with hands-on experiences and opportunities to practice decision making (Keys \& Wolfe, 1990); these experiences and opportunities come in the form of "real" situations that go beyond lecture and other activities that are likely found in classrooms. As a result, students are likely to be more appreciative of the relevance of course content (Burke \& Moore, 2003). More tangentially, simulations have been shown to provide a positive impact on students' self-efficacy (Tompson \& Dass, 2000). Although the literature describes many valuable attributes that simulations offer, we note that the true educational worth of simulations continues to be underestimated. Our purpose here is to provide a more appropriate estimation.

We look at the relationship between business simulations and the educational theory of generative learning. Although generative learning has been examined in many educational settings (Grabowski, 2004), including some settings related to business (Sharp, Knowlton, \& Weiss, in press), a search of electronic databases did not produce any discussion of business simulations as an opportunity for generative learning. Such a discussion is needed for a variety of reasons. Most notably since teaching comprises a large part of a faculty member's service to the academy, we believe faculty members should understand and be able to explain the educational theories underlying their pedagogical and curriculum decisions. We begin here with a brief overview of generative learning. Then we offer a general overview of a specific type of business simulation, the strategic decision- 
making simulation. Finally, we describe how generative learning is inherent to one particular strategic decision-making simulation.

\section{GENERATIVE LEARNING}

Wittrock (1985) describes generative learning as:

(a) the process of generating relationships, or a structure, among the components, or parts, of the information one is trying to comprehend, and (b) the process of generating relationships between one's knowledge and the information one is trying to comprehend (p. 124).

Generative learning strategies promote durable learning by helping students develop connections between course content and students' experiences and knowledge (Wittrock, 1974, 1990, 1992). The empirical literature supporting generative learning techniques is thoroughly reviewed by Grabowski (2004). Proponents of generative learning argue that students, rather than professors, should be engaged in actively pursuing an understanding of course content by completing generative assignments that result in concrete work-products, such as writing assignments, posters, and graphs. Although Wittrock developed the basis of generative strategies, others have developed conceptual frameworks that have translated into pedagogical approaches (Barba \& Merchant, 1990; Johnsey, Morrison, \& Ross, 1992). Jonassen (1988) provides the most direct framework for applying generative strategies, proposing four categories: recall, organization, integration, and elaboration. Three of these strategies are inherent to the simulation experience and will be dealt with here; thus we summarize them briefly. Recall represents the memorization of facts for later restatement, a task that is not a significant part of the simulation process.

\section{Organization}

Organization generative strategies refer to students' efforts with imposing their own structure on content and material. Through the process of imposing a structure, students are shaping that content in ways that make more sense to them, and thus can be better understood by them (Jonassen, 1988). Outlines serve as a basic example, but students also engage in organization when they divide content into categories and subcategories, such as through graphical "concept maps" (Sharp, Knowlton, \& Weiss, in press). Organizational generative strategies may also involve more sophisticated graphical management tools, such as the
Boston Consulting Group (BCG) Matrix used to analyze the potential of different strategic business units, or life cycle models that depict growth of industry sales over time. While these organizational tools are not completely student-created, they provide adaptable cognitive maps that students use to examine business and industry performance.

\section{Integration}

Integration generative strategies allow students to connect new content with their existing thoughts, ideas, and experiences. In essence, students integrate the new with the familiar. Simply asking students to paraphrase or restate an idea in their own words is integrational. Students' own words are fomiliar and thus allow students to understand content in a more familiar light (Wittrock, 1992). A slightly more sophisticated form of integration generative strategy occurs when students connect new content with their own direct experiences. One of the values of a business internship, for example, is providing students with the opportunities to see how basic management concepts, such as management by objectives, play out in the real world. When students connect abstract ideas from a textbook reading with their experiences in a corporate setting, they are integrating the content.

\section{Elaboration}

When learners draw their own conclusions, infer consequences, describe examples, or create analogies, they are engaged in elaboration generative strategies (Jonassen, 1988). Elaboration generative strategies are based on students' efforts to connect new content with extended information-often coming in the form of real-world events or examples. We commonly use this strategy during class discussion. For example, relatively recent headline news, such as the events surrounding Enron, Arthur Anderson, and Martha Stewart, has made discussions of business ethics and agency issues relevant topics for elaboration of the textual material. In this example, students are readily able to give examples of individuals putting their own interests above those of their company for individual gain.

The overview of generative learning in this section provides a framework for understanding the educational theory and how it may be generally applied. Organization, integration, and elaboration strategies create opportunities for students to develop connections between the material they are learning, their experiences, and existing knowl- 
edge. Simulations offer a unique setting for the application of these strategies.

\section{STRATEGIC DECISION-MAKING SIMULATIONS}

To show how generative learning supports the educational viability of business simulations, we focus in the next section on a specific type of simulation, that which provides students with opportunities to engage in strategic decision making. In this section, we offer an overview of strategic decision-making simulations so as to provide a context for what follows.

Strategic decision-making simulations are considered effective practice (Foria, 2001; Walters \& Coalter, 1997) because they focus on the strategic operations of a company within a specific industry. These simulations are set in a variety of industries including airlines, athletic footwear, information technology, and many others. Examples include Corporation (Smith \& Golden, 2003a); Airline: A Strategic Management Simulation Game (Smith \& Golden, 2002); The Business Strategy Game: A Global Industry Simulation (Thompson \& Stappenbeck, 2002); The Business Policy Game: An International Simulation (Cotter \& Fritzsche, 2002); and The Global Business Game: A Simulation in Strategic Management and International Business (Wolfe, 2003).

In general, students are divided into teams, and each team makes decisions about managing their hypothetical company. The decisions represent actions that each team's company takes to operate during a predefined period of time ( 3 or 6 months is common). These decisions may pertain to corporate financing, staffing, pricing, expenditures, and other relevant issues. The decisions of all teams are fed-as responses to variables-into the simulation software by the administrator (usually the course professor or a graduate teaching assistant).

The simulation software calculates performance based upon each team's responses to the decisionvariables, the impact of those variables, as well as interrelationships among those variables (Smith \& Golden, 2003b). In addition, the decisions of each team can affect the outcomes of all teams. That is, all decisions are considered in the software's algorithm to calculate each team's performance visò-vis their competition. Results are then distributed, allowing each team to see the detailed performance of their company alongside some general performance measures of their competitors. This cycle of making decisions and obtaining results occurs repeatedly, with most simulations ending after 6-10 decision cycles have been made. In effect, students are involved in a simulation of managing a company in a competitive situation.

\section{GENERATIVE LEARNING WITHIN SIMULATIONS}

We have claimed that inherent to simulations are opportunities for generative learning. To begin developing this argument, we have provided overviews of generative learning and of a specific type of simulation-the strategic decision-making simulation-that can serve as an example. With these overviews serving as background information, we now substantiate our claims of the inherent relationship between generative learning and simulations by illustrating how one specific strategic decision-making simulation-Smith and Golden's (2003a) Corporation: A Global Business Simulation (hereafter "Corporation")_-gains its educational veracity from the theory of generative learning.

The setting for Corporation is the information systems industry. Smith and Golden (2003a) provide background for the industry and for each company within the industry. A student team is responsible for each company, all of which begin with exactly the same history, characteristics, assets, and liabilities. Each team's company begins with three strategic business units (SBUs): a hardware division, a software division, and a turn-key operation that provides complete integrated systems for customers (Smith \& Golden, 2003a). The authors also provide information on the strategic decisions that are to be determined by each group. These strategic decisions fall into two general categories: corporation level decisions and SBU decisions.

To make clear the theory of generative learning as being inherent to Corporation, we delineate the simulation experience into three phases: the conceptualizing and planning phase, the implementation phase, and the postperformance phase. We offer a brief overview of each and describe how generative learning is evident within each phase. Table 1 serves as a companion to this discussion as it succinctly lists the key activities, type of generative learning produced by key activities, and the generative product created during each phase of the simulation.

\section{Conceptualizing and Planning Phase}

The conceptualizing and planning phase involves more than knowledge acquisition or learning the rules of the simulation. Here students understand and create how their simulated corporation will conduct itself within the industry environment as a competitive, viable, organization. Conceptualization occurs as students make "real" the information provided in the text manual. The student teams make a number of complex decisions that 
TABLE 1

Phase of Simulation, Key Activities, Generative Learning, and Creative Product

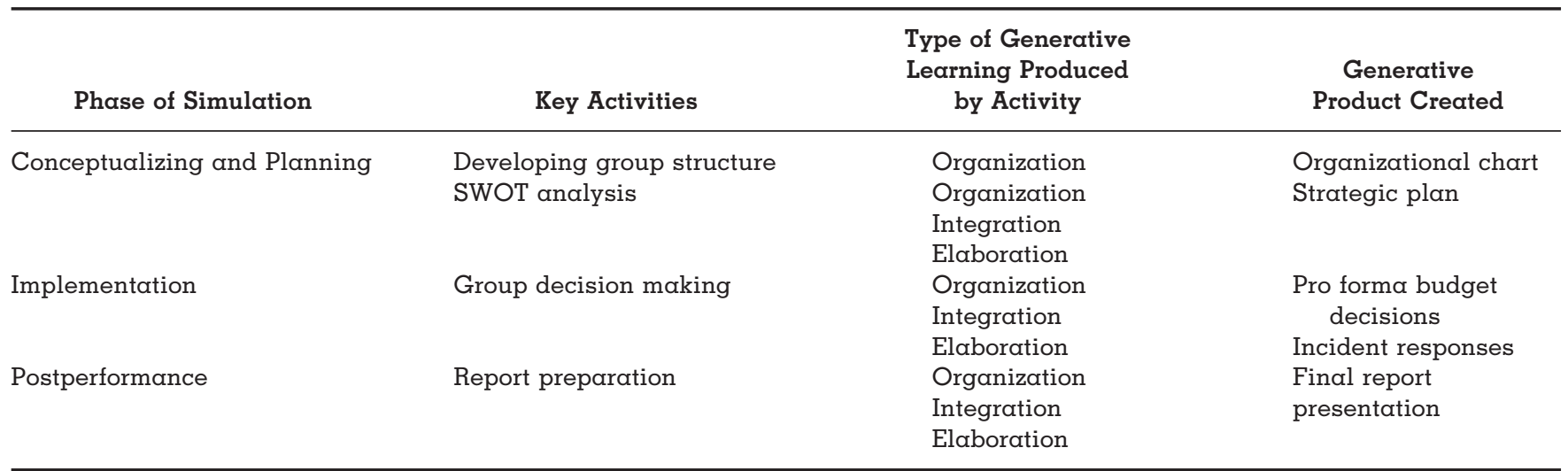

determine the overall nature of their individual corporation and its strategy. Although this phase requires the creation of an organizational chart, the ultimate product of this phase is a studentgenerated product called the strategic plan. This phase requires organization, integration, and elaboration.

\section{Organization}

This initial phase of the simulation requires $a$ great deal of organizational generative learning strategies. Planning represents organizing how the corporation will function, but in order to successfully function, the group itself must organize. The members of the group create an organizational chart that graphically depicts the roles of each group member. It is common for students to select a chief executive officer (CEO) and other positions that relate to other functions required to run the hypothetical company (i.e., chief financial officer (CFO), managers of SBUs, marketing, or other business specialties). This is a method of organization that matches the personnel responsibilities inherent to the simulation with individual member's talents. In our own experience, students commonly recognize parts of the project that meet their skillset and volunteer to take on those responsibilities. For instance, we observe that accounting and finance majors tend to first embrace the quantitative aspects of the simulation, making themselves the group's expert on financial aspects of the simulation. As a part of this process, students organize the information about the simulation, preparing it for integration with their collectively obtained knowledge of business.

\section{Integration}

Also within this first phase, students are, at a basic level, integrating knowledge acquired in previous classes with decisions that they are making to conceptualize their simulated company. The assignments at the beginning of the simulation require an investigation of the information systems industry, combined with use of models that they might have learned in previous courses (i.e., Porter's Five Forces). Such a combination allows students to create ideas and examples of how their simulated company can compete within the simulated industry environment. This exercise, while ostensibly preparing the student for competition within the simulation, is integrational within the framework of generative learning. Students are creating ideas and examples in their own words that are meaningful to them (Jonassen, 1988).

The authors of Corporation recommend that students analyze the strengths and weaknesses of the corporation and opportunities and threats (SWOT) of the industry environment (Smith \& Golden, 2003a). Conducting this SWOT analysis is truly integrational. Analyzing opportunities and threats involves integration of simulation's industry environment with previously acquired understanding of industry environments. This is facilitated by the students' prior knowledge of the information systems industry as consumers, as well as any related management information systems (MIS) coursework. The students formulate ideas pertaining to the simulated industry and its potential opportunities (or threats) based on this knowledge. They pick names for their companies that reflect this understanding, such as "Global Information Systems" or "InfiniTech."

\section{Elaboration}

The analysis of strengths and weaknesses also includes reflection on the resources and capabilities of the corporation as they currently exist, as 
well as how they might be developed to support potential strategies that the corporation might pursue. This elaborative process helps students relate the simulated corporation to the material in the text. Further elaboration of these strategies occurs as the students determine how the strategy would be implemented, and planning occurs. This SWOT analysis provides group members with the information to make organizational decisions that include determining the responsibilities for individual group members, developing a strategy for the corporation and each SBU, and designing methods and plans for implementing each of these strategies. Incorporated into these plans are specific goals and objectives for the company in key areas such as market standing, productivity, profitability, stockholder returns, and ethics.

A product of the planning process is the strategic plan. This is a student-created, written (textual) organization of how the corporation will conduct its business. These strategic plans typically include a mission statement, major goals or objectives, strategy for implementing the goals, and procedures for implementing the strategy. Students create imagery of the potential consequences of the actions, relating the new information through elaboration. This elaboration involves the combination of (a) research of the industry, (b) the course content on strategy, with (c) content from each student's prior major coursework, and (d) prior experience. The result is a synthesis of ideas. In our experience, group discussions involve the complex problems that managers face, such as how their product needs to be marketed, and how they should treat their employees so that the product can be made to meet customer expectations.

\section{Implementation Phase}

In the implementation phase, the teams implement the strategies determined in the conceptualizing and planning. Corporate level decisions are those that determine corporate financing and acquisition or disposition of assets. For example, any of the three SBUs can be sold, and a fourth SBU can be acquired. Also, within each decision cycle, the students must respond to an "incident." Incidents are brief scenarios that a company might face that have potential ethical or performance implications. An example is whether a company should pay bribes (and if so, how much) to local officials overseas where it is customary to do so.

SBU level decisions are those that affect operations, such as price offered for goods or services, and staffing of key personnel. Other SBU-level decisions include medium range decisions reflecting investment in operations technology, product development, and marketing. While the definitions and limits of the issues are frequently specified, the interactivity of one issue to any other is not generally noted. The authors of Corporation (Smith \& Golden, 2003a), for instance, may make allusion to the value of certain expenditures in a given category and how increases in categories may be subject to diminishing returns, but no specific recommendations about decisions are made. For example, in reference to human resource development, the authors state: "Human resources activities such as compensation, training, and careful recruiting may have an impact on productivity, reducing turnover, and increasing demand due to higher quality" (Smith \& Golden, 2003a: 9). They do not indicate how higher productivity might relate to profitability, how increasing demand may allow for higher prices, or more specifically whether a given business strategy might accommodate higher or lower turnover. Like the phase that preceded it, the implementation phase requires organization, integration, and elaboration.

\section{Organization}

Critical to the process of implementation is an understanding of how different business concepts relate to one another. Managing those relationships requires organization. An important organizational tool germane to this phase is a pro forma budget, consisting of an income summary, cash flow analysis, and a balance sheet. These financial reports are compiled in a Microsoft Excel template provided by the authors of Corporation. Beyond organization, the pro forma budget is also helpful because it helps project results of the student's decisions about their corporation.

\section{Integration}

The predictions on which the pro forma is based require integrating examples of strategic management and other business concepts with the specific simulation situation. For example, increasing the quality of the product or lowering price can stimulate demand, while reducing advertising or increasing prices will suppress demand. Effectively managing supply is dependent upon an understanding of all the things that affect demand, including any potential interactions. Likewise, the previously described incidents encountered each period are also integrative in nature and require another student-generated artifact: a written response justifying their choice. A group's justifica- 
tion of why they financed their company's expansion with stock rather than bonds, or how they are going to differentiate their product by investing in research and development, demonstrates that they understand the concepts and are applying them.

\section{Elaboration}

The competitive nature of the simulation during the implementation phase requires continual elaboration as each team pursues alternative courses of action vis-à-vis their competitors. For teams to perform well in the implementation phase, they must be able to recognize the potential consequences of the decisions they make as new performance-related information is presented. Comparing results to predicted information from the pro forma financial information is instrumental to this process.

\section{Postperformance Phase}

The postperformance phase allows students to reflect on their performance in light of their goals and objectives. They critique their performance as managers. The text for Corporation provides questions that focus on the process of the simulation, the reasoning behind the decision making, and the evaluation of their performance (Smith \& Golden, 2003a). Using these questions as a framework, the students produce a written report that contains financial data, evaluation of progress toward goals, and observations of team interactions. This report is formally prepared and the results are presented to the class by each team. The creation of this formal report is an inherently generative process.

\section{Organization}

The report is a written organization of the experiences of the corporation. Results are depicted through graphs that highlight important aspects of financial and other performance indicators. The results are often depicted graphically, providing an organization with large amounts of information.

\section{Integration}

Developing the report involves analyzing the performance of the team. Integration occurs as teams compare their performance to $(\alpha)$ the strategic plan developed in the conceptualization and planning phase, and (b) the performance of other teams. They also integrate concepts from their current and prior coursework, along with their experiences.

\section{Elaboration}

An important aspect of the final report allows the students to elaborate on their experiences, and speculate on alternative courses of action that could have been taken, along with their potential resultant outcomes. Students often use examples from real companies to illustrate what they would try to do differently. For instance, a company that wanted to pursue a cost leadership strategy might refer to making decisions as Wal-Mart might.

\section{CONCLUSION}

We used the generative theory of learning as a lens to closely examine activities that, while commonly associated with strategic decision-making simulations, had not previously been examined this way. Although our discussion focused on one simulation package, perhaps our findings might be generalized to other simulations within the same family. Our findings reveal that opportunities for generative learning occur at all phases of the simulation process, from students' conceptualizing their corporation through a postsimulation review of their own performance. For students, the fun that they have "playing the game" actually hides these important generative learning opportunities. For faculty, awareness of the inherent generative opportunities better prepares them to get the most from the strategic decision-making simulations they use.

We have described the opportunities for generative learning within a specific strategic decisionmaking simulation, but this should be considered as merely a beginning. For example, the generative products described herein (and summarized in Table 1) are comprised of "out-of-the-box" assignments required by the specific simulation package we focused our discussion upon. But, in addition to "stock" assignments, professors could certainly enhance the generative learning opportunities that take place during the simulation experience (through additional writing assignments, activities, etc.). For example, we have required students to reflect in writing on the results of the simulation of each period individually before they discuss the results in their group. They integrate the information in a meaningful way with their understanding of the performance criteria of business and elaborate actions that the group should consider for their company. Other generative assignments could also be developed to compare their company to an actual company in terms of strategy or performance, evaluate their company within the current information systems competitive environment, 
or create specific plans in marketing, production, human resources, or finance. For instance, in Corporation, the group decision to finance their company is made internally. Groups could create a proposal for outside financing that weighed the benefits of all alternatives for the company.

Our examination has demonstrated that activities within the simulation process contribute to learning, but some guidance from the literature regarding the nature and timing of generative activities would be highly valued. In addition, a thorough comparison of various strategic decisionmaking simulations that focuses especially on which better promotes generative learning opportunities would be most useful to the many faculty members that use them.

Finally, while our findings may assist faculty in defining the contribution associated with their use of strategic decision-making simulations, additional research is warranted. Recently, the effectiveness of experiential learning using simulations has been addressed (Gosen \& Washbush, 2004). This is an important area for future research, and the role of generative learning in computerbased simulations may help refine this issue. It may be possible to determine what part of learning occurs from other aspects of the simulation process by studying the learning differences that occur from varying or limiting the generative requirements of the simulation.

\section{REFERENCES}

Association for Business Simulation and Experiential Learning. n.d. Some simulation packages. Retrieved June 13, 2003, from http://www.towson.edu/absel/Packages/packages.html

Barba, R. H., \& Merchant, L. J. 1990. The effects of embedding generative cognitive strategies in science software. Journal of Computers in Mathematics and Science Teaching, 10(1): 59-65.

Burke, L. A., \& Moore, J. E. 2003. A perennial dilemma in OB education: Engaging the traditional student. Academy of Management Learning \& Education, 2(1): 37-52.

Cotter, R. V., \& Fritzsche, D. J. 2002. The business policy game: An international simulation.

Faria, A. J. 1990. Business simulation games after 30 years: Current usage levels. In J. W. Gentry (Ed.), Guide to business gaming and experiential learning: 36-47. East Brunswick, NJ: Nichols/GP.

Faria, A. J. 2001. The changing nature of business simulation/ gaming research: A brief history. Simulation \& Gaming, 32(1): 97-110.

Faria, A. J., \& Wellington, W. J. 2004. A survey of simulation game users, former-users, and never-users. Simulation \& Gaming, 35(2): 178-207.

Gosen, J., \& Washbush, J. 2004. A review of scholarship on assessing experiential learning effectiveness. Simulation \& Gaming, 35(2): 270-293.

Grabowski, B. L. 2004. Generative learning contributions to the design of instruction and learning. In D. H. Jonassen (Ed.), Handbook of research for educational communications and technology (2nd ed., 719-743). New York: Simon \& Schuster Macmillan.

Johnsey, A., Morrison, G. R., \& Ross, S. M. 1992. Using elaboration strategies training in computer-based instruction to promote generative learning. Contemporary Educational Psychology, 17(2): 125-135.

Jonassen, D. H. 1988. Learning strategies in courseware. In D. H. Jonassen (Ed.), Instructional designs for microcomputer courseware: 151-181. Hillsdale, NJ: Lawrence Erlbaum Associates.

Keys, B., \& Wolfe, J. 1990. The role of management games and simulations in education and research. Journal of Management, 16(2): 307-336.

Puto, C. 2004. The next best thing. BizEd, May/June: 44-49.

Sharp, D. C., Knowlton, D. S., \& Weiss, R. E. (in press). Applications of generative learning for the survey of international economics course. Journal of Economic Education.

Smith, J. R., \& Golden, P. A. 2002. Airline: A strategic management simulation same (4th ed.). Upper Saddle River, NJ: Prentice.

Smith, J. R., \& Golden, P. A. 2003a. Corporation: A global business simulation (4th ed.). Upper Saddle River, NJ: Prentice.

Smith, J. R., \& Golden, P. A. 2003b. Instructor's manual for corporation: A global business simulation (4th ed.). Upper Saddle River, NJ: Prentice.

Tompson, G. H., \& Dass, P. 2000. Improving students' self-efficacy in strategic management: The relative impact of cases and simulations. Simulation \& Gaming, 31: 22-41.

Thompson, A. A., \& Stappenbeck, G. J. 2002. The business strategy game: $A$ global industry simulation, version 7.20 . McGraw-Hill/Irwin.

Walters, B. A., \& Coalter, T. M. 1997. Simulation games in business policy courses: Is there value for students? Journal of Education for Business, 72(3): 170-175.

Wittrock, M. C. 1974. Learning as a generative process. Educational Psychologist, 11(2): 87-95.

Wittrock, M. C. 1985. Teaching learner generative strategies for enhancing reading comprehension. Theory Into Practice, 24(2): 123-126.

Wittrock, M. C. 1990. Generative processes of comprehension. Educational Psychologist, 24(4): 345-376.

Wittrock, M. C. 1992. Generative learning process of the brain. Educational Psychologist, 27(4): 531-541.

Wolfe, J. 2003. The global business game: $A$ simulation in strategic management and international business (2nd ed.). Mason, OH: South-Western College Publishing. 
Kenneth Zantow is assistant professor of management in the College of Business at the University of Southern Mississippi. He holds a PhD in management from the University of Arkansas. His research interests include competitive strategy, group performance, management education, and healthcare management.

Dave S. Knowlton holds a doctorate in education from the University of Memphis. He currently is assistant professor of instructional design and learning technologies at Southern Illinois University-Edwardsville. His research interests include learning theory and instructional strategies. Learn more about his professional work by visiting www.siue.edu/ dknowlt.

David C. Sharp is assistant professor of economics and Business Advisory Council Research Professor in the College of Business at the University of Southern Mississippi. He holds a PhD in economics from the University of Memphis. His research interests include applied microeconomics, managerial economics, strategy, econometrics, and economic education. 
Copyright of Academy of Management Learning \& Education is the property of Academy of Management. The copyright in an individual article may be maintained by the author in certain cases. Content may not be copied or emailed to multiple sites or posted to a listserv without the copyright holder's express written permission. However, users may print, download, or email articles for individual use. 